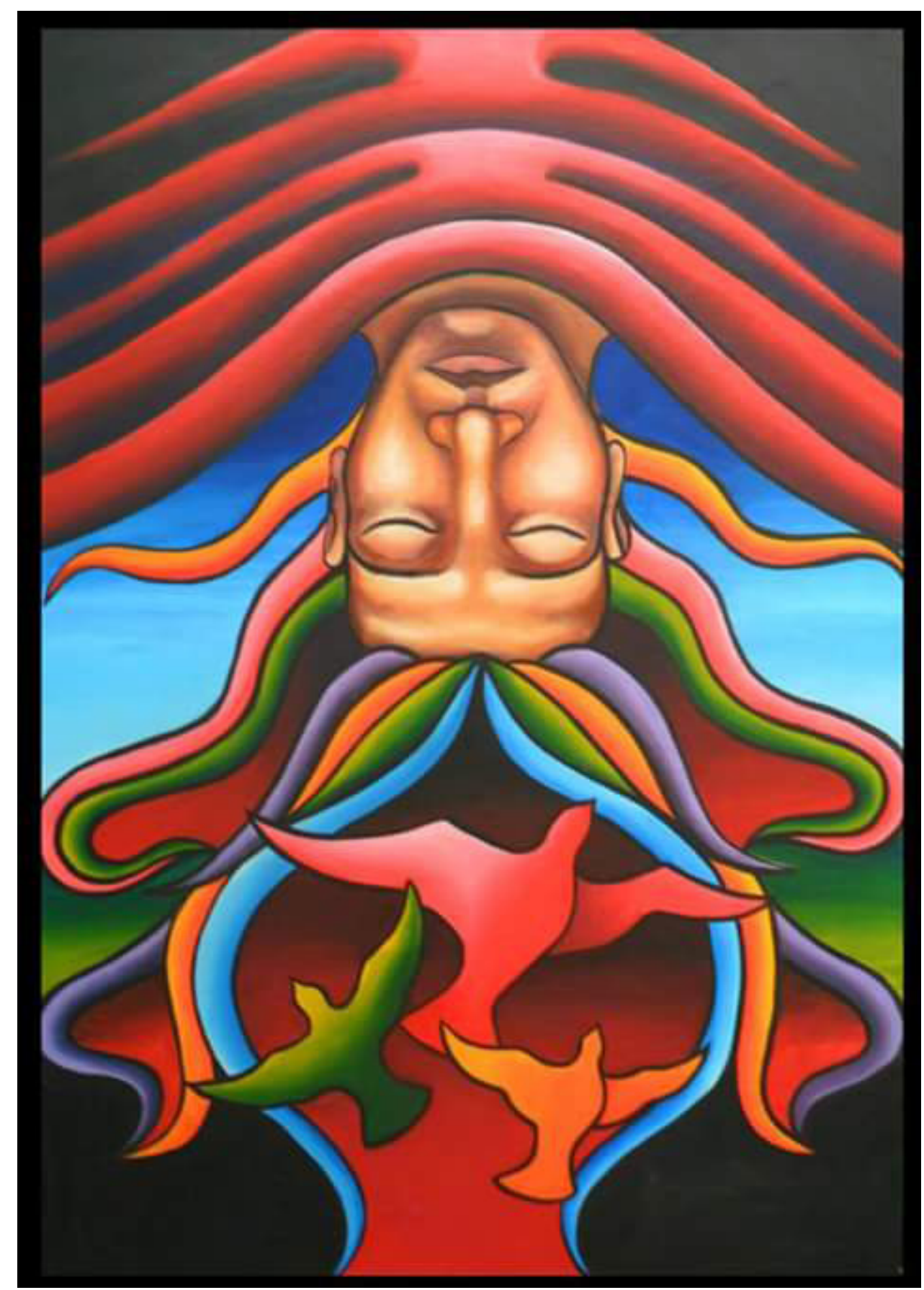

Artista: Heri Tapia 


\title{
Argumentación, Comprensión y Polifonía. Reflexiones desde el aula de clase universitaria
}

\author{
ARGUMENTATION, UNDERSTANDING, AND POLYPHONY. REFLECTIONS FROM \\ THE UNIVERSITY CLASSROOM \\ $\square$ RACIOCÍNIO, COMPREENSÃO E POLYPHONY. REFLEXÕES A PARTIR DA CLASSE \\ EM AULAS DE FACULTADE
}

Jennifer Rivera Zambrano1 / riverazjennifer@gmail.com

Resumen

El presente artículo plantea un problema que afecta la enseñanza y el aprendizaje de habilidades comunicativas y argumentativas en el espacio académico universitario, con el fin de sugerir algunas ideas para futuros desarrollos. La pregunta que orienta esta reflexión es: ¿Cómo abordar la demanda de comprensión por parte de los estudiantes de pregrado en la elocución oral y escrita? Para resolver dicho interrogante, se hará el abordaje de tres asuntos: (a) el aporte de un enfoque dialéctico de la argumentación, (b) las características hermenéuticas de la comprensión y (c) la importancia de los fenómenos de polifonía del lenguaje en la construcción de sentido.

\section{Abstract}

This article considers a problem affecting teaching and learning communicative and argumentative skills in the university academic space, in order to suggest some ideas for future developments. The question that guides this reflection is: How to address the demand for understanding by undergraduates in oral and written elocution? To solve this question, it will be done the approach of three issues: (a) the contribution of a dialectical approach of argumentation, (b) the hermeneutical characteristics of understanding and (c) the importance of the phenomena of polyphony of language in the construction of meaning.

Resumo

Este artigo surge com a intenção de indicar um problema que afeta o ensino ea aprendizagem das habilidades comunicativas e argumentativos em um espaço acadêmico, para sugerir algumas idéias para futuros desenvolvimentos. A pergunta que orienta esta reflexão é: como lidar com a demanda para a compreensão dos alunos de graduação em elocução oral e escrita? Para resolver esta questão abordando três questões terá lugar: 1. o fornecimento de uma abordagem dialética à argumentação, 2. as características de compreensão hermenêutica e 3. a importância dos fenômenos da polifonia da linguagem na construção de sentido

Fecha de recepción: 08 de agosto de 2015 / Fecha de aprobación: 05 de septiembre de 2015
Palabras clave

polifonía, comprensión, lenguaje, argumentación, habilidades comunicativas

Keywords

polyphony, understanding, language, argumentation, communication skills

Palavras-chave

polifonia, compreensão, linguagem, raciocínio, habilidades de comunicação

1 Profesora del Programa de Filosofía. Investigadora, grupo Cultura y Sociedad, de la Facultad de Ciencias Sociales y Humanas, Universidad Externado de Colombia. 


\section{Introducción}

La expresión oral y escrita ocupa un lugar preponderante en la formación académica del pregrado; en particular, cuando se pone en juego la necesidad de justificar la opinión, por cuanto esta alude a desafíos y aprendizajes tales como los niveles de claridad con los que se producen los enunciados, los juegos gramaticales, el valor semántico y, por supuesto, las estructuras argumentativas, desde donde las ideas son formuladas bajo la forma de juicios; en general, en asignaturas propedéuticas, como Lógica y Argumentación, Taller de Lenguaje, Pensamiento Crítico, Habilidades Comunicativas, etc., se busca, por un lado, mostrar al estudiante las herramientas lógicas que tienen lugar en espacios y contextos conversacionales propios, y, por otro, indicar nuevas técnicas que refuercen la pertinente práctica de la oralidad y la escritura académica. Así pues, si observáramos una de estas clases, nos encontraríamos con desarrollos y actividades acerca de preguntas por la cuestión de la que se propone hablar en el texto o en una conversación, la acción que se da a entender con el enunciado, la relación y la implicación del contexto de enunciación, los contenidos que aluden al asunto en cuestión y hallar un orden de enunciación en relación con la idea por desarrollar. Todo eso tiene sentido a la luz de los retos, los desarrollos y las inquietudes de los estudiantes en este nivel, pues, finalmente, no sobra indicar que, en gran medida, de dichas asignaturas dependerán el éxito estudiantil y la adecuada presentación de un proyecto de grado, por no extendernos en otros asuntos que aquí también estarían involucrados.

Entre los retos destaco algunos que entran en juego recurrentemente en las sesiones de clase. El primero es acerca de los momentos en que el texto indica una acción con variados sujetos gramaticales; o cuando el sujeto desaparece de la variedad de acciones. En la oralidad, esto puede suceder por el recurso de la economización del lenguaje, y también, por la gestualidad en sintonía con los enunciados, cosa que no sucede en la escritura. Por ello, se enseñan contenidos de gramática y de semántica. Pero, además, la expresión oral o escrita supone entender que el uso del lenguaje construye sentido, y que, de acuerdo al ordenamiento de dichas estructuras básicas, esa sumatoria va a configurar un sentido común y comunicable. Normalmente, en la vida cotidiana lo que nos encontramos es que cuando aparece la pregunta por el sentido de tales afirmaciones, la respuesta más común es: "la verdad es que yo no quería decir eso". Nos encontramos con que lo que el texto dice es otra cosa distinta de la que se quería enunciar, y ahí tenemos otro problema: ¿Cómo lograr que el estudiante diga lo que quiere decir? No se debe olvidar que los estudiantes de pregrado llegan a la universidad con un conocimiento y una experiencia del manejo de la lengua. En el colegio 2 se exige la apropiación de unos conocimientos, que, sin embargo, cambian notablemente en la universidad, en términos de amplitud y de exigencia, y que tienen que ver también con el papel crítico que el estudiante va a desempeñar como universitario, y más adelante, como profesional.

En términos de la argumentación, esta dificultad se expresa en una discrepancia entre entender las estructuras argumentativas, los esquemas, los tipos, las relaciones entre premisas y conclusiones y su aplicación a un discurso argumentativo. Parece como si al momento de elaborar un discurso, todas esas nociones tendieran a desaparecer. Y, más aun, el planteamiento y la defensa de un punto de vista se ven nublados por el hecho de que el hablante mismo no entiende la afirmación que ha postulado como conclusión, y la cual, se supone, expresa su propia posición frente al asunto en discusión. Entonces, la pregunta es: ¿Cómo enfrentar los retos que esta situación nos plantea como educadores? Considero que lo primero es evitar seguir viendo la argumentación con una perspectiva demasiado estrecha; esto es, como el seguimiento de formas argumentativas de convalidación de las relaciones entre premisas y conclusiones. Los aportes de teorías contemporáneas como la teoría pragma-dialéctica de la argumentación nos permiten ver la argumentación como la práctica comunicativa que, en efecto, es. Pero ello solo sirve de entrada para pensar el problema señalado: ¿cómo abordar esta demanda de comprensión por parte de los estudiantes? Algunos docentes hemos dicho que una teoría de la comprensión como la hermenéutica

\footnotetext{
2 Los recientes cambios que ha promovido el Instituto Colombiano para la Evaluación de la Educación (ICFES) con la planeación de un enfoque filosófico transversal en la educación media. A lo que se refiere con enfoque filosófico es al desarrollo de habilidades comunicativas; específicamente, en lo concerniente a un posicionamiento crítico que conduzca a la comprensión del carácter inferencial de los textos, entre otros asuntos que entran en juego en estas pruebas (ver políticas nacionales 2015)
} 
nos brinda diversas soluciones, pues la hermenéutica propone unas condiciones, gracias a las cuales, si el lector las tiene claras, puede acercarse con mayor facilidad a un documento o a plantear una posición crítica. Sin embargo, aun en medio del aparato conceptual y explicativo de la hermenéutica, escapa, oculto por la bruma ontológica, el fenómeno más simple, relacionado con el hecho de que lo dicho siempre es algo que se sale de las manos, por cuanto es un fenómeno lingüístico polifónico. Sobre estos tres asuntos: un enfoque dialéctico de la argumentación, las características de la comprensión y la polifonía del lenguaje, versará el presente artículo, con el ánimo de plantear un problema que afecta la enseñanza y el aprendizaje de la argumentación y de la lengua misma, y así sugerir algunas ideas para futuros desarrollos.

\section{La teoría pragma-dialéctica}

No es de mi interés entrar en esta ocasión en un debate sobre la teoría pragma-dialéctica de la argumentación y sus conceptos. La razón de iniciar con esta aproximación consiste en resaltar el carácter dialógico de la práctica comunicativa que envuelve toda argumentación. Y que ese carácter dialógico obliga a ubicar la cuestión que nos interesa en el nivel pragmático del uso de lenguaje, por ser allí donde se localiza la inquietud por el sentido. Si la cuestión del sentido se limitase meramente a un problema semántico o formal, podría resolverse con una fórmula; pero las discrepancias de sentido aparecen cuando se busca establecer una interacción comunicativa con otro. Por ello, resulta útil recurrir aquí a dicho planteamiento teórico. En $A$ Systematic Theory of Argumentation, Van Eemeren y Grootendorst (2004) definen la argumentación como "una actividad verbal, social y racional dirigida a convencer un crítico razonable de la aceptabilidad de un punto de vista mediante el planteamiento de una constelación de proposiciones que justifican o refutan la proposición expresada en el punto de vista" (p. 1). Con esta definición, los autores buscan dejar claros los siguientes puntos: (a) la argumentación es algo que tiene lugar por medio del uso del lenguaje; (b) la argumentación es una actividad social, pues solo tiene sentido implementarla en el caso de la interacción con un otro que la demanda; (c) la argumentación apela a unas consideraciones intelectuales en su proceder, $y$, finalmente, (d) la argumentación implica un criterio de relevancia de su ejecución en relación con un particular punto de vista que es puesto al menos en duda por un otro con quien se interactúa, y con quien, de común acuerdo, se está en disposición a enfrentar la duda por medio de consideraciones intelectuales, tal que quien duda pueda reconsiderar sus dudas en virtud de la aceptabilidad del punto de vista defendido.

En esta aproximación a la argumentación, Van Eemeren plantea la necesidad de entender la argumentación como un acto de habla. Esto distingue el acto de habla argumentativo de la unidad textual "argumento" (una estrategia textual y formal que carece de sentido sin un contexto de comunicación). Por otra parte, el hecho de que este acto de habla sea parte de una actividad social conlleva una demanda de unas condiciones de razonabilidad que los usuarios del lenguaje habrán de seguir y esperar de aquellos con quienes interactúan. Esta expectativa es lo que permite considerar la argumentación en una perspectiva dialógica, pues la interacción requiere, para llegar a su meta — esto es, resolver una diferencia de opinión (un desacuerdo entre dos partes respecto a uno o más puntos de vista)—, seguir un procedimiento razonable y aceptable por las partes en conflicto. A este procedimiento los autores lo denominan una discusión crítica. Van Eemeren plantea un modelo de discusión crítica que funciona como instrumento de análisis y evaluación del discurso argumentativo (Van Eemeren, Grootendorst \& Snoeck Henkemans, 2006). El modelo de discusión crítica expone, a través de cuatro etapas -la etapa de confrontación, la etapa de apertura, la etapa de argumentación y la etapa de conclusión-, las condiciones de inicio y procedimentales de un discurso argumentativo. Respecto a los estándares críticos, que se requieren para evaluar la argumentación, este procedimiento es regulado, según Van Eemeren, a través de 10 reglas del procedimiento de una discusión crítica ${ }^{3}$. Dichas

3 Las reglas señaladas son las siguientes: Regla 1: Las partes no deben impedirse unas a otras el presentar puntos de vista o ponerlos en duda; Regla 2: Una parte que presenta un punto de vista está obligada a defenderlo si la otra parte le solicita hacerlo; Regla 3: El ataque de una parte en contra de un punto de vista debe referirse al punto de vista que realmente ha sido presentado por la otra parte; Regla 4: Una parte solo puede defender su punto de vista presentando una argumentación que esté relacionada con ese punto de vista; Regla 5: Una parte no puede presentar algo falsamente como si fuera una premisa dejada implícita por la otra parte, ni puede negar una premisa que él mismo ha dejado implícita; Regla 6: Ninguna parte puede presentar falsamente una premisa como si fuera un punto de partida aceptado, ni puede negar una premisa que representa un punto de partida aceptado; Regla 7: Una parte no puede considerar que un 
reglas plantean un código de "conducta ideal" del argumentador, tal que, si son respetadas por las partes de la discusión crítica, podrán llegar, en principio, a una solución a su diferencia de opinión.

Como ya he mencionado, no entraré a debatir este planteamiento. Lo interesante resulta en mostrar que la argumentación puede ser considerada más allá de las fórmulas lógicas, y así podemos adentrarnos en lo característico de la experiencia de expresión de los estudiantes. ¿Puede el estudiante concebirse a sí mismo, cuando enfrenta la tarea de realizar un texto argumentativo, como una parte razonable y crítica de una discusión? Si la respuesta es afirmativa, como cabe esperar por parte de todos, ¿por qué en medio de esa interacción aparecen las discrepancias de sentido? Para cualquier docente resultará notorio que cuando estas aparecen, el procedimiento de la discusión se ve bloqueado; incluso, a veces, hay que volver a empezar. La teoría pragma-dialéctica no ofrece herramientas para evaluar la razón de esta incomprensión; puede que, dentro del marco de esta teoría, se trate de hacer explícita una de las diez reglas y mostrar en qué momento se descarriló el discurso. Pero aun el enunciado de la regla misma se encuentra sujeto al hecho de la incomprensión, y eso nos lleva a un círculo irremediable e improductivo. El problema del sentido de lo dicho es algo que aún requiere mayor atención por parte de teorías contemporáneas de la argumentación, como la que hemos presentado someramente, pues si podemos ubicar la argumentación en la práctica comunicativa e interaccional, ahí mismo tendremos que enfrentar el éxito o fracaso en la construcción y la comunión del sentido de lo dicho. Por esto, debemos revisar alternativas probablemente complementarias.

punto de vista ha sido defendido concluyentemente si la defensa no se ha llevado a cabo por medio de un esquema argumentativo apropiado que se haya aplicado correctamente; Regla 8: En su argumentación las partes solo pueden usar argumentos que sean lógicamente válidos o que sean susceptibles de ser validados explicitando una o más premisas implícitas; Regla 9: Una defensa fallida de un punto de vista debe tener como resultado que la parte que lo presentó se retracte de él y una defensa concluyente debe tener como resultado que la otra parte se retracte de sus dudas acerca del punto de vista; Regla 10: Las partes no deben usar formulaciones que resulten insuficientemente claras o confusamente ambiguas y deben interpretar las formulaciones de la parte contraria tan cuidadosa y tan exactamente como les sea posible (Van Eemeren \& Grootendorst, 2009).
¿Primero comprender, luego argumentar?

Como ya se dijo, un recurso podría ser apelar a una reflexión acerca de la comprensión misma, pues ella parece ser no solo el opuesto de las discrepancias de sentido que generan incomprensiones, sino una condición para poder entablar una interacción comunicativa. Posturas hermenéuticas como la de Hans George Gadamer indican que el ejercicio de la comprensión estriba en el posicionamiento de una actitud abierta que hace del proceso de la comprensión un verdadero resultado interpretativo. Porque comprender, en primer lugar, es leer. Leer, para la hermenéutica, implica escuchar, y, en tanto oyente, poder participar de lo dicho, verlo a través de la experiencia particular, por lo que ya habría una interpretación.

En esta perspectiva, recordemos que Gadamer, fiel al diálogo con la tradición, retoma el concepto de experiencia proveniente de la fenomenología husserliana, en la que experimentar "algo" es percibirlo; específicamente, "verlo". Y, precisamente, porque lo experimentado es percibido, ocurre la experiencia; de ahí su inmediatez constituyente (Husserl, 1999). Esta inmediatez tiene que ver con ser consciente de lo percibido como algo que es, que está ahí y no requiere demostración, pues, precisamente, ocurre en la experiencia, en la percepción. La percepción, entonces, es la forma básica de la conciencia que implica no solo oír, sino una validación que se da en el ver, una experimentación de lo que el texto afirma.

Si toda comprensión implica interpretación, este experimentar se constituye en tres principios de la comprensión internos al oír y ver de la lectura. Es fácilmente reconocible que en la discusión frente a un texto académico surjan fácilmente desviaciones de la opinión del discurso, malentendidos (dados por nuestras propias limitaciones). Frente a lo cual, la propuesta gadameriana afirma que, en lugar de dejarse desviar por los propios malentendidos respecto a las limitaciones que el lector pueda tener, el primer principio remite a un dejarse determinar por la cosa misma. La dinámica de dicho proceso estriba en el reconocimiento de un primer sentido, sobre el que se establece (el lectorintérprete) un proyecto previo que pretende proyectar un sentido del texto. Este proyectarse es leer con base 
en determinadas expectativas previas el texto, anticipaciones que permiten vislumbrar el sentido propio del texto. Sin embargo, el proyecto está sujeto a revisión en el proceso de la comprensión. De este modo, progresivamente se reproyecta por la unidad del sentido. Es un movimiento de sentido, de comprobación y de sustitución, del comprender e interpretar.

En este primer principio se busca, a través de las anticipaciones, corresponder de manera correcta al texto o, como diría Gadamer, a la cosa. Este proceso se da exitosamente si la opinión previa no es arbitraria frente al texto. Por ello, debe ser un movimiento constante de reapropiación y cercanía de la proyección con el texto original. Una contextualización del ámbito lingüístico — diferencia en el uso del lenguaje-, del tiempo y del autor (Gadamer, 1991).

Aunque el proceso descrito pareciera muy genérico, para Gadamer el texto tendría un - lo Ilamo yosentido global que limitaría la comprensión incorrecta. Para él, una comprensión incorrecta mantenida generaría inmediatamente la destrucción del sentido del conjunto, lo que Ilevaría al lector a reconocer la desviación, en tanto se aleja cada vez más de la opinión original. Pero, además, se tendrían que reconocer ciertos patrones o planteamientos de tipo prejudicial. Aquí los prejuicios equivalen a aseveraciones positivas que se forman antes de su convalidación, y permiten poner el texto en contexto con base en la posibilidad de dejarse decir algo (Gadamer, 1991).

El segundo principio hace referencia a la historia efectual. La comprensión aquí se define en la relación del hombre con el mundo, de manera histórica; el hombre asume una posición respecto a su acontecer personal. En tanto partícipe de la historia, el sujeto asume una posición crítica respecto a lo que acaece. De aquí que el texto sea confrontado con su estar en el mundo y que esta carga histórica permita tener una experiencia dialógica con base en la tra-dicción lingüística trasmitida y recolectada. Este "ser histórico" comprende desde unas condiciones históricas determinadas.

El tercer principio alude a la fusión de horizontes. Esta remite a la imbricación del pasado con el presente a través del dominio de la historicidad del lector (en términos de Gadamer, la tradición -personal y cultural). De lo que aquí se trata es de la influencia de estar en el mundo en una línea temporal compartida en función del bagaje cultural.

La fusión tiene lugar constantemente en el dominio de la tradición; pues en ella lo viejo y lo nuevo crecen siempre juntos hacia una validez Ilena de vida, sin que lo uno ni lo otro lleguen a destacarse explícitamente por sí mismos. (Gadamer, 1991, p. 377)

Esta posibilidad permite ver el texto desde un espectro abarcante; no solo personal, sino histórico.

Ahora bien, esta teoría expone el comprender como la capacidad para interactuar con otra posición en un diálogo abierto. Toda vez que alguien se permite leer un texto, está dejando que otro le muestre una percepción de mundo. He aquí el riesgo y la ganancia de la lectura: riesgo si lo que es dicho es incomprendido: comprendido inadecuadamente; y ganancia si se logra reconocer el sentido de tal. Vale la pena preguntarse cuál es la garantía de este verdadero sentido, la comprensión correcta, y, ¿por qué no?, si realmente se puede llegar a ella. Es probable que dicha regla no se cumpla en todos los casos, pues, tal vez, el texto no cuenta con las condiciones para su adecuada comprensión; salvo este posible, en la mayoría de los casos, según Gadamer, se debería lograr la comprensión.

El caso de la incomprensión plantearía que para poder comprender un texto debe haber como condición de posibilidad unos prerrequisitos que tienen que ver con poder entrar en diálogo con el texto. En ello estaría mediando el sentido, pues leer permite "ver" imágenes a partir de un significante directo que se correspondería con el lenguaje. Es, precisamente, por la presencia de imágenes por lo que vale la pena asumir una posición crítica. Asumir una posición crítica supone tener qué decir frente a lo planteado, reconocer los límites y los alcances de la propuesta, para permitirnos planear nuevas discusiones, condiciones de afirmación o de neutralidad. Sin embargo, después de saber esto — que el lector tiene la posibilidad de dejarse determinar por el texto, que es un sujeto histórico y que puede entrar en diálogo con la tradición; en suma, que las condiciones del círculo hermenéutico son pertinentes 
para que se dé la comprensión-, considero que las situaciones de incomprensión demuestran la necesidad de atender a esa instancia previa mediadora que es el sentido y las demandas que plantea al lector incluso antes de dar lugar a la comprensión. Reconocer los principios de la comprensión no es suficiente todavía para dar el paso entre qué es lo que se comprende y cómo se comunica. Las condiciones gadamerianas, si bien aportan, no son suficientes, o, al menos, no solucionan en su totalidad el problema del sentido en la relación entre comprender y comunicar un texto.

Una alternativa a esta cuestión es recurrir a la polifonía, pues ésta plantea que lo dicho y cualquier acto de habla en general supone reconocer que esa afirmación, que es emitida de manera oral o escrita, está constituida según múltiples ideas, planteamientos, procesos o condiciones que, regularmente, el interlocutor no reconoce. Pongamos un ejemplo: cuando me encuentro con un compañero por la calle que me dice: "el viernes vamos a tomar unas copas", yo respondo "sí, claro", y espero el viernes a que me llame, pero resulta que nadie Ilama. Y cada vez que nos encontramos, este personaje me dice exactamente lo mismo. ¿Qué es lo que está sucediendo en estas ocasiones? El punto es que tal situación del habla puede no ser clara, porque, a pesar de la enunciación, hay una relación primero contexto-dependiente, en términos de costumbres muy particulares, regionales, con las que no siempre todo hablante o todo oyente está familiarizado. Además, bajo dicha afirmación se encuentra un juego de diversos personajes que están allí y permiten consolidar ese tipo de locución como una que se dice cortésmente, pero no tendrá realización. Entonces, en la medida en que no se comprenden "las voces" que hacen parte del juego en el cual está inmersa la locución, se hace más difícil comprender el enunciado, o se comprende de manera literal, como fue mi caso. Ahondemos en el asunto.

\section{Polifonía y argumentación}

La "voz" aparece en este escenario como un concepto importante, que voy a abordar a partir de algunos puntos de la polifonía lingüística, que Oswald Ducrot (1988) presenta en su texto Polifonía y Argumentación, pues es a través de la polifonía como estimo que se pueden entender las (in)comprensiones de un enunciado. En primer lugar, parto de que, para poder llegar a una comprensión pertinente, se debe reconocer que la información, o lo expresado, está mediado por distintos elementos que siempre tienen lugar en las enunciaciones. Ducrot lo desarrolla de la siguiente manera: para él, los enunciados están pletóricos de un sinnúmero de actantes/actores/posición de enunciación (o en términos de Foucault, sujetos de enunciación). La enunciación, cuando se expresa, no se plantea de manera directa, pues el autor no se expresa directamente, sino que en la expresión habría otro cierto número de personajes o sujetos que hablan y construyen el sentido, como condiciones externas de producción del enunciado. Esto lleva a considerar que no hay un predominio de unicidad del sujeto hablante.

Por el contrario, Ducrot presenta al menos tres tipos de personajes (funciones) en un enunciado expresado: el autor hablante o el sujeto empírico, el locutor y el enunciador. De estos tres agentes del discurso se dejará de lado el autor, en tanto no es problemático para la justificación, pues se asume que es quien expresa el enunciado. Este sujeto empírico corresponde al autor efectivo. En adición, a dicho autor se le agrega la siguiente condición: según Ducrot, siempre que se habla se habla de algo que ya existe, porque en la mayoría de los casos el autor se remite a informaciones que no son de su propiedad. Por ello, se puede decir que, en general, los discursos que se enuncian son repeticiones escuchadas con antelación (Ducrot, 1988).

El segundo personaje es el locutor. Este, por su parte, es quien tiene la responsabilidad de la enunciación en el enunciado. El anuncio de un diseño del medio ambiente que en su copy tenga el enunciado "cuídame" da cuenta de que el medio ambiente "es el presunto responsable del enunciado".

El tercer personaje es el enunciador. Este remite a los puntos de vista referentes a los contextos en los que se originan los enunciados: "todo enunciado presenta un cierto número de puntos de vista relativos a las situaciones de las que se habla" (Ducrot, 1988, p. 19). Estos espacios mentales o universos de creencias aluden a las perspectivas que están presentes y sustentan el sentido del enunciado. En la expresión: '¡Ah, muy bonito!', hay 
dos puntos de vista posibles: por un lado, en el contexto de relojes en una tienda supondrá un locutor que tiene un punto de vista apreciativo frente al objeto; pero, por otro lado, el mismo enunciado en el contexto de una mamá con un hijo supondrá un locutor que tiene un punto de vista de reproche frente a alguna actitud. La cuestión aquí es que el enunciado por sí mismo tiene la posibilidad de dos enunciadores que alternativamente adquieren sentido en función del caso.

En el ejercicio de clase se le exige al estudiante una aproximación a los textos cuyo sentido se espera sea capaz de identificar. Sin embargo, el sentido es resultado también del reconocimiento de estas tres funciones que posee el enunciado. Cuando esto no ocurre, el estudiante confunde el locutor con el enunciador y con el autor. Veamos un ejemplo. Un texto trabajado en clase que ilustra el problema es Una humilde propuesta, de Jonathan Swift. La tesis de este texto es que los bebés de los mendigos pueden ser ofrecidos como manjar a los ricos para solucionar el problema de hambruna en Irlanda en el siglo XVIII. Este enunciado se justifica mediante una argumentación rigurosa que legitima el acto. La cuestión aquí es que, aparte de las sucesivas críticas que los estudiantes plantean a tal tipo de alternativa económica, algunas veces no se reconoce que dichos enunciados se plantean desde un punto de vista estrictamente satírico, que apunta a criticar la indiferencia de la clase poderosa frente a la pobreza. Diríamos, entonces, que: 1) el desconocimiento del autor impide ubicar el contexto del texto; 2) esta carencia genera la confusión entre el locutor y el enunciador - asumir que Swift es el proponente responsable de la defensa del canibalismo-y el punto de vista de la crítica social queda eliminado; es decir, el punto de vista absurdo que subyace a los enunciados es tomado como el locutor de la propuesta, aun cuando este sea el enunciador. Un caso como este ilustra que si no se tiene en cuenta el juego de los actantes, el texto mismo no podría ser comprendido, a causa de las incomprensiones de las funciones del enunciado.

Podría señalarse que debido a la elipsis que supone la sátira, las connotaciones incorporadas en el texto de Swift plantean un problema de mayor complejidad, al que estaría acostumbrado un estudiante de primeros semestres de universidad -este punto, empero, es cuestionable, pues también el lenguaje irónico hace parte de las maneras como las y los jóvenes se expresan y demuestran que no son extraños a su uso. Pero, por demás, un fenómeno similar ocurre frente a textos típicamente académicos. El asunto también se evidencia cuando se les pide a los y las estudiantes un análisis argumentativo. En la universidad se exigen competencias de discusión crítica, de argumentación, en las que no siempre han sido preparados. Aunque ellos lo lean y relean, usualmente no logran reconocer el sentido, pues un argumento demanda una relación con un contexto, la intertextualidad (en una discusión está implícito el antagonista), la voz del autor, las posiciones actanciales y la responsabilidad del locutor. En otras palabras, no se sigue que, por ser un argumento, el enunciado sea claro por sí mismo. Veamos otro ejemplo.

En su análisis de la pena de muerte en Estados Unidos, David Bruck argumenta que la pena capital es inválida debido a su efecto de discriminación racial. Sugiero que ese razonamiento va demasiado lejos. Si como sospecho, es verdadero, los jueces y los jurados imponen todas las penas más duramente a los negros que a los blancos (o más duramente cuando la víctima es blanca), el análisis del señor Bruck conduciría a la conclusión de que toda sanción criminal es inválida. (Edward Fletcher III, carta al editor de The New Republic, 1984. Tomado de Copi \& Cohen, 2007)

Este argumento hace parte de un conjunto de ejercicios de un célebre texto de introducción a la lógica que hoy se sigue usando para iniciar el entrenamiento en habilidades argumentativas. En este caso, el argumento los pone frente a un gran tropiezo, que estriba en la necesidad de reconocer las voces que lo constituyen. Las condiciones externas de producción del sentido del mencionado argumento son varias y variadas; por un lado, está la del autor, Fletcher; por otro, la posición del señor Bruck, y estas, a su vez, son constituidas por posiciones actanciales como, por ejemplo, para no ir más lejos, el planteamiento según el cual las personas afro se ven involucradas mayormente en situaciones criminales que las personas de tez blanca. Otra podría ser la posición jurídica respecto a los derechos y los deberes de los ciudadanos en lo concerniente a las penas y su jurisdicción. A esta podemos agregar la posición actancial que alude a las injusticias, los casos 
de exclusión e invisibilización de grupos minoritarios, de género, de orientación sexual; también, cómo hoy por hoy las leyes estatales defienden y promulgan la alteridad y la diferencia. Finalmente, aunque pueden surgir muchas más, se puede reconocer la posición actancial que alude al racismo como componente fundamental en la toma de decisiones de los tribunales. Al desconocer este panorama actancial o de enunciador, se generan los malentendidos a los cuales nos vemos comúnmente avocados en el aula de clase: normalmente, los estudiantes asumen que el argumento está justificando la eliminación de la pena capital en razón del racismo, punto de vista que hace parte de la función del enunciador, y no necesariamente del locutor ni del autor; en otras palabras, no se logra fácilmente la comprensión del papel de objeción que desarrolla el escrito.

Por lo anterior, la in-comprensión no puede jugar un papel errático en la comprensión de la argumentación. Las demandas que plantean la construcción de sentido, ya de un enunciado o ya de una composición compleja como un argumento, puestas en el juego social y comunicativo de dar y pedir razones, no se resuelven con una aproximación formal ni codificada en normas pragmáticas (como las planteadas por la pragma-dialéctica). Por el contrario, y, precisamente, por tratarse de un fenómeno lingüístico, la polifonía nos plantea la necesidad de ampliar las habilidades de análisis hacia el reconocimiento de las múltiples voces que componen el sentido. De ahí que la enseñanza de la argumentación y la de la lengua en general impliquen el reconocimiento de que lo que se afirma en un discurso argumentativo no pertenece meramente a quien lo dice, sino que su sentido también se compone de las múltiples voces que juegan en la identificación y la validación de lo dicho. Seguramente, una de las muchas funciones de la docencia en materia de las habilidades comunicativas consiste en mediar entre la propia voz del estudiante y el mundo de voces que componen un texto, para, con ello, lograr las condiciones de comprensión esperadas y, a su vez, el posicionamiento crítico argumentado frente a lo leído.

Así, para finalizar, cabe retomar algunas conclusiones de lo aquí planteado en las voces de los tres autores puestos en diálogo. La teoría pragma-dialéctica, tal como ha sido esbozada, nos permite ubicar la argu- mentación, pues frente al panorama presentado de la incomprensión, pensar en la argumentación ( $y$, más aún, en su enseñanza) requiere reconocer e incentivar el papel de los estudiantes como participantes de una discusión crítica (ya sea explícita o implícitamente con otro individuo o un texto), en cuya pragmática es donde aparecen las dificultades señaladas para construir y comunicar a otros el sentido de una enunciación. Si bien en la teoría de Van Eemeren no se manifiesta interés por abordar dicha cuestión más allá de un posible descarrilamiento de una regla de discusión crítica, es posible resaltar la importancia de abordar — críticamente- un enfoque dialógico, donde el estudiante sea invitado a asumir el rol de una de las partes de la discusión, para, con ello, hacer manifiestos los momentos de incomprensión.

Dada la relevancia de lo dialógico, la hermenéutica nos pone de frente a la importancia del carácter histórico y situado de la comprensión; con esta perspectiva, la comprensión de lo expresado no se reduce a esclarecer el significado de las palabras, sino que se amplía en una dinámica constitutiva de la experiencia misma de vivir en un mundo pletórico de significaciones, tanto por la relación con la tradición como por la identificación del presente. De esta manera, la comprensión de lo dicho, de un punto de vista o de un discurso completo abarca múltiples relaciones contextuales y experienciales que permanentemente confrontan a cualquier individuo $-y$ que, en suma, básicamente, reconstruye la experiencia misma de los estudiantes.

Finalmente, estas relaciones contextuales no se limitan a aspectos situacionales alternos al lenguaje mismo. La teoría de la polifonía de Ducrot tiene la virtud de llevarnos al núcleo más básico de la incomprensión: el sentido yace también en el hecho de que lo que decimos, una vez puesto en la vida social, ya no es nuestro. Existe un conjunto de relaciones que expresan las voces con las cuales interactuamos en la argumentación. Lo dicho reitera, pero también construye otras voces que demandan ser identificadas para reconocer el "punto en cuestión". De hecho, en una discusión crítica —esto es, en una argumentación con perspectiva pragma-dialéctica-, existen al menos dos voces que remiten a las partes de la discusión, y, a la vez, cada una puede traer a colación otras a favor de sus respectivas posiciones; voces que, 
además, estarán marcadas por el horizonte de comprensión del hablante. Así, en términos de la argumentación, debemos lograr que los estudiantes pasen de sentir desazón por su incomprensión a convertirla en una oportunidad de plantear una diferencia de opinión que pueda, dialógicamente, ampliar su propia comprensión y la de aquellos con quienes interactúa sobre los enunciados cuyas voces, a veces, nos resultan difíciles de atender, y que, empero, hacen parte de nuestras maneras de relacionarnos y entender nuestra realidad. Puede que la argumentación misma no sea sino una permanente interacción entre múltiples voces en torno a un mismo asunto, incluso cuando argumento conmigo misma en la tarea de escribir. Es también posible que la incomprensión no sea meramente una dificultad, sino el lugar necesario del desacuerdo entre voces que dan vida a la argumentación misma.

\section{Referencias}

Copi \& Cohen, (2007). Introducción a la lógica. México: Limusa.

Ducrot, O. (1988). Polifonía y argumentación. Cali: Universidad del Valle.

Gadamer, H. G. (1991). Verdad y método. Salamanca: Sígueme.

Gadamer, H. G. (1997). Mito y razón. Barcelona: Paidós.

Gadamer, H. G. (1998). Arte y verdad de la palabra. Barcelona: Paidós.

Husserl, E. (1999). Investigaciónes lógicas I. Madrid: Alianza.

Van Eemeren, F. \& Grootendorst, R. (2004). A systematic theory of argumentation. Cambridge: Cambridge University Press.

Van Eemeren, F., Grootendorst, R. (2009). Reglas para una discusión crítica. Praxis filosófica,28, enero-junio.

Van Eemeren, F., Grootendorst, R. \& Snoeck Henkemans, F. (2006). Argumentación: análisis, evaluación, presentación. Buenos Aires: Biblos.

\section{Diálogo del conocimiento}

El artículo Argumentación, comprensión, y polifonía. Reflexiones desde el aula de clase universitaria de Jennifer Rivera Zambrano sostiene la siguiente tesis: un estudiante universitario podrá obtener competencias comprensivas y argumentativas frente a un texto (ya sea oral o escrito) si logra transitar, al menos, en tres planos: (1) uno pragma-dialéctico, (2) uno hermenéutico y, finalmente, (3) uno polifónico.

Para fundamentar dicha tesis, la autora hace un breve diagnóstico de los retos que surgen cuando los estudiantes intentan comprender un texto. Estos retos son cuatro: (1) poder identificar los variados sujetos que están inmersos en el texto, (2) lograr expresar lo que se quiere decir sobre el texto, (3) aplicar correctamente los diferentes "formalismos" argumentativos a la argumentación situada y, finalmente (4) lidiar con las discrepancias de sentido que surgen en la lectura del texto.

Para lograr superar estos retos, el estudiante debe poder transitar en tres "planos": el pragma-dialéctico, el hermenéutico (o comprensivo) y el polifónico:

\section{El pragma- dialéctico}

En este plano el estudiante puede lograr, al menos, dos asuntos. El primer asunto es que el estudiante pueda concebir el diálogo, la comprensión y la confrontación con un texto (oral o escrito) en un nivel pragmático, es decir, en la interacción comunicativa y social con el otro. Esta interacción comunicativa se sitúa más allá de las reglas formales, pues la comprensión del sentido de un texto no puede estar dada totalmente por el conocimiento y la aplicación de reglas formales a una interacción comunicativa. De otro lado, el segundo asunto, haría del estudiante un "interlocutor crítico" en una discusión crítica, puesto que éste sería capaz de dar y pedir razones cuando se requiere aclarar una duda (incomprensión) que surge a partir del contenido del texto. 


\section{El hermenéutico (o comprensivo)}

En este plano el estudiante encuentra elementos para comprender el sentido del texto o elementos que le permitan enfrentar a las diversas incomprensiones que surgen en la discusión crítica. La autora, siguiendo a Gadamer, dice que en este plano se logran visibilizar tres aspectos: la escucha (dejarse determinar por la cosa misma), la historia efectual y la fusión de horizontes. En estos tres aspectos, los estudiantes logran situar lo enunciado en el texto en un marco referencial histórico (contextual) que puede coincidir o divergir con su horizonte de comprensión.

\section{El polifónico}

En este plano los estudiantes encuentran diferentes "voces" que les permiten "perfeccionar" sus habilidades comprensivas y argumentativas frente al sentido de un texto. El estudiante en este plano sería capaz de reconocer tres tipos de "voces o "personajes": la voz del hablante, la voz del locutor y la voz del enunciante. El reconocimiento de estas voces permitiría al estudiante reconocer el sentido del texto para que, de este modo, las incomprensiones que surjan puedan integrarse en una discusión crítica.

Víctor Eligio Espinosa Galán 